\section{A Physic Tensile Forces Ex- periment to Possible Explain the Reason of Failing Ventral Hernia Repair}

\author{
Eldo E Frezza $^{1^{*}}$, Cory Cogdill ${ }^{2}$, Mitchell Wacthell ${ }^{3}$ and Edoar- \\ do GP Frezza ${ }^{4}$
}

${ }^{1}$ Health Science Center, Eastern New Mexico University, Roswell NM, USA

${ }^{2}$ Mathematics, Physics and Science Department, Eastern New Mexico University, Roswell NM, USA

${ }^{3}$ Texas Tech University, Lubbock TX, USA

${ }^{4}$ University of Delaware, Newark DE, USA

\begin{abstract}
Introduction: Ventral hernia repair, a challenging procedure. We consider rubber bands, evaluating the strength of bands of differing length and thickness to see how changes in these parameters affect the elastic materials to try to mimic how abdominal muscle get affected by tensile forces.

Methods: Four sets of six rubber bands were evaluated: A) thick, medium length, B) thick, longest length, $C$ ) thin, medium length and D) thin, short length. Thickness and length of rubber bands were measured using a Vernier caliper. Each rubber band was attached to a string attached to a stabilized paper clip. Increasing weight was applied until each rubber band broke. The maximum weight was converted to maximum tensile strength by dividing the weight in Newton's by the cross sectional error. Effects of width and length upon maximal tensile strength were analyzed by statistical two pair analysis and log gamma regression.

Results: Log Gamma regression revealed an interaction between thickness and length; the coefficients for an increase in width by $1 \mathrm{~mm}(-0.63)$ and length by $1 \mathrm{~cm}(-0.53)$, which decreased maximum strength were countered by a strengthening from a combined

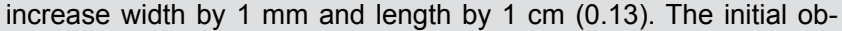
servations showed that a thicker elastic material (red rubber band) holds more weight than a thinner one (yellow) despite similar length $(\mathrm{P}<0.0001)$.

Discussion: The effects of increasing muscle strength and the circumference of the abdominal wall cannot be considered in isolation.
\end{abstract}

*Corresponding author: Eldo E Frezza, Health Science Center, Eastern New Mexico University, Roswell NM, USA, Tel: +1 956-357-7355; E-mail: eefrezza@ msn.com

Citation: Frezza EE, Cogdill C, Wacthell M, Frezza EGP (2017) A Physic Tensile Forces Experiment to Possible Explain the Reason of Failing Ventral Hernia Repair. J Gastroenterol Hepatology Res 2: 007.

Received: July 12, 2017; Accepted: August 21, 2017; Published: September 06,2017
The muscle component of the ventral hernia is one of many variables affecting the abdominal wall. In this paper we focus on that issue understanding the complexity of the pathology. Our goal is to show how stress force act on any material and assuming that they do the same on the human body. We can hypostasize the notion that hernia is secondary to shear forces and because of this repair of the entire abdominal wall therefore is the only solution.

Keywords: Abdominal wall physiology; Component separation; Cross sectional area; Elastic bands; Elastic force; Mesh; Newton's/ $\mathrm{cm}^{2}$; Tensile force; Tensile stress; Ventral hernia repair; Ventral hernia; Ventral hernia repair

\section{Introduction}

Ventral Hernia Repair (VHR) has been a challenging surgery during years. Matters moved to mobilizing muscle and closing the abdominal wall. Component Separation Repair (CSR), which required dissection of the fascia of the rectus muscle and closure of the midline linea alba [1]. The goal of ventral hernia repair is to restore abdominal muscle strength and abdominal wall function $[2,3]$. The muscle component of the ventral hernia is one of many variables affecting the abdominal wall to contribute to ventral hernia. In this paper we focus on that issue understanding the complexity of the pathology. We hypothesized that evaluating the maximal stress on a set of artificial tensile structures, rubber bands, might open a different view on the effects of daily forces affecting the strength of varied abdominal walls.

\section{Materials and Methods}

Four sets of six rubber bands were evaluated (Table 1).

In the first comparison, we matched rubber band based on their thickness of $0.1 \times 0.35 \mathrm{~cm}$ : A) short $(4.2 \mathrm{~cm})$, high strength rubber bands (red bands) (modeled the young person with much muscle strength and flexibility, B) long $(7 \mathrm{~cm})$, high strength rubber bands of longer length (white bands) modeled abdominal walls with fully stretched muscle, but with similar strength, such as occurs after pregnancy or with obesity. In the second comparison, we match the length $(4.2 \mathrm{~cm})$ and change the thickness: A) thick $(0.1 \times 0.35 \mathrm{~cm})$, rubber bands (red bands) as above and $\mathrm{C})$ thin $(0.1 \times 0.1 \mathrm{~cm})$, rubber bands (yellow bands) modeled elderly or protein deficit patients, obese patient who had experienced an operation. We then use for final comparison a D) thin and short band $(0.1 \times 0.1 \times 2 \mathrm{~cm})$.

Thickness, width and length of the bands were measured using a vernier caliper. The four bands were then stressed with progressively increasing weights at $20 \mathrm{~g}$ increments. Weight at the time of failure was recorded for each of six trials of each band type (Table 1).

The Tensile strength was measured in force per cross-sectional area. All the data is reported and compared in table 1. The units of force were derived by multiplying mass $(\mathrm{kg})$ by the acceleration of gravity $\left(9.81 \mathrm{~m} / \mathrm{sec}^{2}\right)$ per Newton's second law of motion $(\mathrm{F}=\mathrm{m} \mathrm{x} \mathrm{a})$. This results in a force unit of Newton. The tensile strength was measured by taking the weight (Newton) and dividing it by the cross-sectional area $\left(\mathrm{cm}^{2}\right)$. Tension and shear forces were summarized to create the condition to apply the log regression (Tables 2 and 3). 
Citation: Frezza EE, Cogdill C, Wacthell M, Frezza EGP (2017) A Physic Tensile Forces Experiment to Possible Explain the Reason of Failing Ventral Hernia Repair. J Gastroenterol Hepatology Res 2: 007.

- Page 2 of $4 \cdot$

\begin{tabular}{|c|c|c|c|c|}
\hline \multicolumn{5}{|c|}{ Rubber Band A (Red) - thick and medium length } \\
\hline & \multirow{2}{*}{$\begin{array}{c}\text { Dimensions }=0.1 \mathrm{x} \\
0.35 \times 4.2 \\
\text { Mass hung at } \\
\text { failure }(\mathrm{kg})\end{array}$} & \multicolumn{3}{|c|}{ Cross sectional area $=0.035 \mathrm{~cm}^{2}$} \\
\hline & & Force $(\mathrm{N})$ & Stress $\left(\mathrm{N} / \mathrm{cm}^{2}\right)$ & Stress $\left(\mathrm{Ibs} / \mathrm{in}^{2}\right)$ \\
\hline Trial 1 & 3.75 & 36.82 & 1051.91 & 1525.15 \\
\hline Trial 2 & 3.84 & 37.69 & 1076.86 & 1561.32 \\
\hline Trial 3 & 3.72 & 36.5 & 1042.94 & 1512.15 \\
\hline Trial 4 & 3.32 & 32.52 & 929.15 & 1347.15 \\
\hline Trial 5 & 3.72 & 36.44 & 1041.26 & 1509.71 \\
\hline Trial 6 & 2.24 & 21.97 & 627.84 & 910.29 \\
\hline Mean & 3.43 & 33.66 & 961.66 & 1394.3 \\
\hline STD & 0.61 & 6.00 & 171.38 & 248.48 \\
\hline
\end{tabular}

\begin{tabular}{|c|c|c|c|c|}
\hline \multicolumn{4}{|c|}{ Rubber Band B (White) - thick and longest length } & \\
\hline & \multirow{2}{*}{$\begin{array}{c}\text { Dimensions }=0.1 \times \\
0.35 \times 7 \mathrm{~cm} \\
\text { Mass hung at } \\
\text { failure }(\mathrm{kg})\end{array}$} & \multirow[b]{2}{*}{ Force $(\mathrm{N})$} & \multicolumn{2}{|c|}{$\begin{array}{c}\text { Cross sectional area }=0.035 \\
\mathrm{~cm}^{2}\end{array}$} \\
\hline & & & Stress $\left(\mathrm{N} / \mathrm{cm}^{2}\right)$ & Stress (Ibs/in²) \\
\hline Trial 1 & 2.72 & 26.66 & 761.82 & 1104.55 \\
\hline Trial 2 & 2.36 & 23.17 & 662.03 & 959.87 \\
\hline Trial 3 & 2.26 & 22.13 & 632.32 & 916.8 \\
\hline Trial 4 & 3.23 & 31.65 & 904.2 & 1310.99 \\
\hline Trial 5 & 3.12 & 30.56 & 873.09 & 1265.88 \\
\hline Trial 6 & 2.95 & 28.94 & 826.84 & 1198.83 \\
\hline Mean & 2.77 & 27.19 & 776.72 & 1126.15 \\
\hline STD & 0.4 & 3.91 & 111.6 & 161.81 \\
\hline
\end{tabular}

\begin{tabular}{|c|c|c|c|c|}
\hline \multicolumn{5}{|c|}{ Rubber Band C (Yellow) - thin and medium length } \\
\hline & \multicolumn{2}{|c|}{$\begin{array}{c}\text { Dimensions }=0.1 \times 0.1 \mathrm{x} \\
4.7(\mathrm{~cm})\end{array}$} & \multicolumn{2}{|c|}{ Cross sectional area $=0.01 \mathrm{~cm}^{2}$} \\
\hline & $\begin{array}{l}\text { Mass hung at } \\
\text { failure }(\mathbf{k g})\end{array}$ & Force $(\mathrm{N})$ & Stress $\left(\mathrm{N} / \mathrm{cm}^{2}\right)$ & Stress $\left(1 \mathrm{bs} / \mathrm{in}^{2}\right)$ \\
\hline Trial 1 & 0.88 & 8.66 & 866.22 & 1255.92 \\
\hline Trial 2 & 0.74 & 7.29 & 728.88 & 1056.8 \\
\hline Trial 3 & 1.18 & 11.61 & 1160.52 & 1682.62 \\
\hline Trial 4 & 0.9 & 8.86 & 885.84 & 1284.37 \\
\hline Trial 5 & 0.98 & 9.64 & 964.32 & 1398.16 \\
\hline Trial 6 & 1.1 & 10.79 & 1079.1 & 1564.57 \\
\hline Mean & 0.97 & 9.47 & 947.48 & 1373.74 \\
\hline STD & 0.16 & 1.56 & 155.68 & 225.72 \\
\hline
\end{tabular}

\begin{tabular}{|c|c|c|c|c|}
\hline \multicolumn{5}{|c|}{ Rubber Band D (Blue) - thin and shortest length } \\
\hline \multicolumn{2}{|c|}{$\begin{array}{c}\text { Dimensions }=0.1 \times 0.1 \mathrm{x} \\
2.0 \mathrm{~cm}\end{array}$} & \multirow[b]{2}{*}{ Force $(\mathrm{N})$} & \multicolumn{2}{|c|}{ Cross sectional area $=0.01 \mathrm{~cm}^{2}$} \\
\hline & $\begin{array}{l}\text { Mass hung at } \\
\text { failure }(\mathbf{k g})\end{array}$ & & Stress $\left(\mathrm{N} / \mathrm{cm}^{2}\right)$ & Stress $\left(1 \mathrm{bs} / \mathrm{in}^{2}\right)$ \\
\hline Trial 1 & 2.65 & 26 & 742.76 & 1076.91 \\
\hline Trial 2 & 3.15 & 30.9 & 882.9 & 1280.1 \\
\hline Trial 3 & 2.45 & 24.03 & 686.7 & 995.63 \\
\hline Trial 4 & 3.05 & 29.92 & 854.87 & 1239.46 \\
\hline Trial 5 & 3.25 & 31.88 & 910.93 & 1320.74 \\
\hline Trial 6 & 2.85 & 27.96 & 798.81 & 1158.19 \\
\hline Mean & 2.9 & 28.45 & 812.83 & 1178.51 \\
\hline STD & 0.31 & 3.02 & 86.39 & 125.26 \\
\hline
\end{tabular}

Table 1: Maximum Stress for each rubber band by band group

Rubber Band A (Red) - thick and medium length; Rubber Band B (White) - thick and longest length; Rubber Band $\mathrm{C}$ (Yellow) - thin and medium length; Rubber Band D (Blue) - thin and shortest length

\begin{tabular}{|c|c|c|c|c|}
\hline \multicolumn{5}{|c|}{ Force and Stress Analysis } \\
\hline & \multicolumn{2}{|c|}{$\begin{array}{c}\text { Dimensions }=0.1 \times 0.1 \times 2.0 \\
\mathrm{~cm}\end{array}$} & \multicolumn{2}{|c|}{ Cross sectional area $=0.01 \mathrm{~cm}^{2}$} \\
\hline & $\begin{array}{l}\text { Mass hung at } \\
\text { failure (kg) }\end{array}$ & Force (N) & Stress $\left(\mathbf{N} / \mathrm{cm}^{2}\right)$ & Stress $\left(\mathrm{Ibs} / \mathrm{in}^{2}\right)$ \\
\hline Trial 1 & 2.65 & 26 & 2599.65 & 3769.19 \\
\hline Trial 2 & 3.15 & 30.9 & 3090.15 & 4480.36 \\
\hline Trial 3 & 2.45 & 24.03 & 2403.45 & 3484.72 \\
\hline Trial 4 & 3.05 & 29.92 & 2992.05 & 4338.12 \\
\hline Trial 5 & 3.25 & 31.88 & 3188.25 & 4622.59 \\
\hline Trial 6 & 2.85 & 27.96 & 2795.85 & 4053.66 \\
\hline Mean & 2.9 & 28.45 & 2844.9 & 4124.77 \\
\hline
\end{tabular}

Table 2: Force and stress analysis.

\begin{tabular}{|c|c|c|c|c|c|c|}
\hline Coefficient & Exp(est) & Estimate & SE & T & P & \\
\hline Intercept & 12078.5 & 9.39918 & 0.1779 & 52.834 & $<2 \mathrm{e}-16$ & $* * *$ \\
\hline Width $\uparrow \mathbf{1} \mathbf{~ m m}$ & 0.53181 & -0.63147 & 0.08546 & -7.389 & $\begin{array}{c}3.89 \mathrm{E}- \\
07\end{array}$ & $* * *$ \\
\hline $\begin{array}{c}\text { Length } \uparrow \mathbf{1} \\
\mathbf{c m}\end{array}$ & 0.58299 & -0.53959 & 0.04676 & -11.54 & $\begin{array}{c}2.70 \mathrm{E}- \\
10\end{array}$ & $* * *$ \\
\hline $\begin{array}{c}\text { Width } \uparrow \mathbf{1} \mathbf{~ m m} \\
\mathbf{\&} \text { Length } \\
\uparrow \mathbf{1} \mathbf{~ c m}\end{array}$ & 1.14153 & 0.13237 & 0.01789 & 7.398 & $\begin{array}{c}3.82 \mathrm{E}- \\
07\end{array}$ & $* * *$ \\
\hline
\end{tabular}

Table 3: Results of log gamma regression.

Experimental procedures: Cross sectional area was the product of the width and thickness in centimeters. Units of force were the product of the maximum mass $(\mathrm{kg})$ and the acceleration of gravity $(9.81$ $\left.\mathrm{m} / \mathrm{sec}^{2}\right)$ per Newton's second law of motion $(\mathrm{F}=\mathrm{m} \mathrm{x}$ a), measured in Newton's. Tensile strength was the number of Newton's divided by the cross-sectional area $\left(\mathrm{cm}^{2}\right)$.

Statistical analysis: T-test for two independents (non-pooled standard error) was used to compare the bands two at the time. All statistical measures included 6 data points for each band. Log gamma regression was used to evaluate the effect of changes in width and length upon maximum tensile strength.

\section{Results}

Rubber band measurements, mass hung at failure measurements and calculated maximal tensile strength measurements are recorded in table 1 . We notice that the thicker and short rubber band was the strongest (red), the longest rubber band was the weakest in regards to the tensile stress $\left(\right.$ Newton $/ \mathrm{cm}^{2}$ ). The Red and White bands had a significant difference at alpha $=0.10$ since the $p$ value was 0.055 . The Yellow clearly held much less weight and was significantly different than the other three $\mathrm{P}=0.000$. The yellow band held much less than the other two the mean mass held by the red was $3.43 \mathrm{~kg}$ and the yellow was $0.97 \mathrm{~kg}$. Failure is most often occurred at either the top or the bottom of the band. One of the challenges was to load the masses in a careful manner without adding additional forces due to dropping the weights abruptly onto the hook that held the weights. By repeating the same experiment with thinner cross-sectional area of $0.01 \mathrm{~cm}^{2}$ between Yellow and Blue band we confirm the data that when the thickness is the same the factor that contribute to hold more weight is shorter length in this case the blue $(2.0 \mathrm{~cm})$ vs the yellow $(4.7 \mathrm{~cm})$. 
All rubber bands broke in a similar fashion, nearly always at the top or the bottom of the rubber band. Results of log gamma regression are recorded in tables 2 and 3, with each of the coefficients being highly statistically significant $(\mathrm{P}<0.0001$ for each assessment). No violations of generalized linear methods were seen. No important outliers were observed.

The regression equation estimated by $\log$ gamma regression is: Maximum strength $=\log (12078.47-0.63 \mathrm{x}$ Width $(\mathrm{mm})-0.53 \mathrm{x}$ Length $(\mathrm{cm})+0.13 \mathrm{x}$ Width $\mathrm{x}$ Length). Note that the relationship is logarithmic. An increase in width of $1 \mathrm{~mm}$ without a change in length is associated with a maximum tensile strength that is $53 \%$ of the thinner rubber band. An increase in length of $1 \mathrm{~cm}$ without a change in width is associated with a maximal tensile strength that is $58 \%$ of the shorter rubber band. An interaction is present, such that each $1 \mathrm{~cm}$ longer and $1 \mathrm{~mm}$ wider rubber band is associated with a maximal tensile strength that is $14 \%$ greater than the thinner, shorter rubber band, apart from the differences imparted from the changes in length and width themselves.

The effect of changes in length and width thus depend upon the length and the width. Examples best illustrate this. The result of decreasing a $3 \mathrm{~mm}$ wide $5 \mathrm{~cm}$ long band to a $1 \mathrm{~mm}$ wide $5 \mathrm{~cm}$ long band is: $(1-3) \times-0.63+(1 \times 5-2 \times 5) \times 0.13=-0.96$; a $1 \mathrm{~mm}$ wide $5 \mathrm{~cm}$ band has $\exp (-0.06)=94 \%$ of the maximum stress of a $3 \mathrm{~mm}$ wide $5 \mathrm{~cm}$ long band. The result of increasing a $3 \mathrm{~mm}$ wide $5 \mathrm{~cm}$ long band to a $3 \mathrm{~mm}$ wide $6 \mathrm{~cm}$ long band is: $(6-5) \times-0.53+(3 \times 6-3 \times 5) \times 0.13=$ -0.14 ; a $3 \mathrm{~mm}$ wide $6 \mathrm{~cm}$ long band has $\exp (-0.14)=87 \%$ of the maximum stress of a $3 \mathrm{~mm}$ wide 5 long $\mathrm{cm}$ band. The result of changing a $3 \mathrm{~mm}$ wide $5 \mathrm{~cm}$ long band to a $1 \mathrm{~mm}$ wide $6 \mathrm{~cm}$ long band is: (1-3) $\mathrm{x}-0.63+(6-5) \times-0.53+(1 \times 6-3 \times 5) \times 0.13=-0.46$; a $1 \mathrm{~mm}$ wide $6 \mathrm{~cm}$ long band has exp $(-0.46)=63 \%$ of the maximum stress of a 3 $\mathrm{mm}$ wide 5 long $\mathrm{cm}$ band.

\section{Discussion}

The muscle component of the ventral hernia is one of many variables affecting the abdominal wall to contribute to ventral hernia. In this paper we focus on that issue understanding the complexity of the pathology. Therefore we evaluated specifically on the effect of muscle and try to mimic that on the rubber material.

\section{Comment on the experiment}

4 different types of rubber bands were used. The initial observations showed that a thicker elastic material (Red rubber band) holds more weight than a thinner one (Yellow) despite similar length $(\mathrm{P}<0.0001)$. It seems therefore that thickness is the major contributor for holding more weight, and therefore the cross sectional area, since when we compare thinner but shorter rubber band (Blue) to a longer but thicker rubber band (White), the thicker rubber band was holding more pressure.

Then to confirm the data we use bands with same thickness (Red and White) with cross sectional area of $0.35 \mathrm{~cm}^{2}$ but different in length: 4.2 vs $7 \mathrm{~cm}$ (Red vs White) and we found at if the thickness is the same short length is the factor that contribute to give strength to the material making holding more weight $(\mathrm{P}<0.55)$. By repeating the same experiment with thinner cross sectional area of $0.01 \mathrm{~cm}^{2}$ between yellow and blue band we confirm the data that when the thickness is the same the factor that contribute to hold more weight is shorter length in this case the blue $(2.0 \mathrm{~cm})$ vs the yellow $(4.7 \mathrm{~cm})$.

Our second part of the experiment (Tables 2 and 3) focused on comparing all the rubber bands strength confirmed the longest rubber band was the weakest regarding the tensile stress $\left(\right.$ Newton $\left./ \mathrm{cm}^{2}\right)$. The shorter red rubber band held the greatest weight. Note that the wider the band is initially, the greater the effect of the change in length would be and vice versa; that's where the explanation problems come in.

This gives us a way to compare different materials based upon the same cross-sectional area. The tensile strength is about 1.5 times the shear strength in material. If then we considered the length of the rubber band we notice that comparing bands with the same thickness red and white the difference in strength is significant different with a confidence level of $\mathrm{a}=95$, making the red band the strongest.

Log Gamma regression revealed an interaction between thickness and length, such that individual increments in width and length decreased maximal stress while their combined effects increased maximum stress; the coefficients for an increase in width by $1 \mathrm{~mm}(-0.63)$ and length by $1 \mathrm{~cm}(-0.53)$, which decreased maximum strength, were countered by strengthening from a combined increase width by $1 \mathrm{~mm}$ and length by $1 \mathrm{~cm}(0.13)$.

\section{The clinical issues}

Abdominal wall defect represents a difficult surgical problem requires appropriate management for acceptable results. The component separation method and autologous tissue repair that has been employed for such a situation with satisfaction by many with mesh [3-5]. This type of component separation is recommended with the associated entire fistula, ileostomy, colostomy closure and other potential infection procedure simultaneously performed but lately this type of approach has been developed on all ventral hernias because this gives like a complete repair of the abdominal wall and can be used also in initial ventral hernia recurrence or any complications [6-8]. We compared different thickness rubber bands and length to mimic the behavior of a tensile material as the abdominal wall and find the "breaking point". This is the point where the material stretched to the point of non-return. This happened to abdominal wall for instance during multiple pregnancies where the abdominal wall muscle cannot get their shape back and lost their elasticity and power to contract.

The increased physiological stress of the greater operative duration on a patient who often has multiple co morbidities seems to place a significant role in predicting the recurrences outcome $[9,10]$. This physiological stress seems to be directly correlated with the physic and tensile strength and it is an important concept because in this case, the authors pointed out that the physiological stress during the surgery but forgot to mention the physiological stress of the patient before the surgery that creates the situation that brought the patient to surgery [11-13].

For decades, we considered that the problem of the hernia was the "hole", but we find out that it is the product of physiological rearrangement of muscle fibers and fascia, that stretched for different reason: pregnancy, obesity, old age and trauma etc. Physic helped us to put this into prospective since this is not typical just to the muscle but to all elastic and stretchable materials. Our simple experiment showed that applying force to an elastic material we reached the point of no return, did not matter if it was thick or short. At that time, we can throw the rubber band away. But what to do with the abdominal muscle? Given this observation the only solution available to take care of the real problem of ventral hernia it is to use fresh muscle and therefore the only techniques who allow this is the component separation where we can mobilize muscle from the side and bring it to the midline. 
The open component separation allows autologous tissue repair with approximation of a midline fascia in patients with complex hernia. But of course, create large skin flaps where instead the endoscopic one is performed without the vision of the epigastric vessels. Short term recurrence though between the open and the laparoscopic technique is comparable [14-18]. Other surgeons, when faced with a ventral hernia choose between higher incidence recurrent repair or complication and it has been shown that the laparoscopic repair and the component separation are the two evolving strategies to repair the ventral hernia, one to repair the midline, as we said, and one to repair the whole abdominal wall [19-22].

A review of a complication between 2005 and 2010 was performed by Fischer who identified patients by code for ventral hernia repair in concomitant component separation [6]. This was in a very interesting study because it was done using the American College of Surgery National Surgical Quality Improvement Program (ACS-NSQIP) patient database. The independent variable included medical co morbidities, comparative consideration and patient's demographics, major comparative complications such as deep wound infection; graph or prosthetic loss or plan to return to the operating room within 30 days was used as a dependent variable. The logistic regression was performed to evaluate patient risk and this showed the greater operative times and overall patient's health are important prognostic factors for individuals going after abdominal wall reconstruction. We are doing more works in this arena to compare tensile strength in elastic materials that would accurately model the muscle tissue strength. In addition, it would be helpful to compile clinical data that would identify if failure is between the mesh and the muscle (as a shear force) or if the reoccurrences.

In our clinical experience the redo surgery in the Ventral Hernia Repair (VHR) group were those with the highest BMI 54 compare with 39 averages when they have their hernia repairing the first place? An increase in BMI instead was the higher indication for hernia repair for the group with Component Separation Repair (CSR). The latter in fact had higher BMI than the VHR group showing that obesity and gain weight can play a role in the hernia formation and loss of abdominal physiology. The CSR group though despite the higher BMI had less recurrence, showing an improvement by repair the whole abdominal wall.

\section{Conclusion}

In this experiment, we tried to focus on material and showed the breaking point of it. We are very aware that muscle is not a material and cannot be directly compare to it. Our goal is to show how stress force act on any material and assuming that they do the same on the human body. Looking at our result we can hypostasize the notion that hernia is secondary to shear forces affecting the muscle and fascia. Repair of the entire abdominal wall therefore is the only solution.

\section{References}

1. Pauli EM, Rosen MJ (2013) Open ventral hernia repair with component separation. Surg Clin North Am 93: 1111-1133.

2. Criss CN, Petro CC, Krpata DM, Seafler CM, Lai N, et al. (2014) Functional abdominal wall reconstruction improves core physiology and quality of life. Surgery 156: 176-182.

3. Koltz PF, Frey JD, Bell DE, Girotto JA, Christiano JG, et al. (2013) Evolution of abdominal wall reconstruction: development of a unified algorithm with improved outcomes. Ann Plast Surg 71: 554-560.
4. Lasses Martínez B, Peña Soria MJ, Cabeza Gómez JJ, Jiménez Valladolid D, Flores Gamarra M, et al. (2017) Surgical treatment of large incisional hernias with intraperitoneal composite mesh: a cohort study. Hernia 21: 253-260.

5. Pomahac B, Aflaki P (2010) Use of a Non-Cross-Linked Porcine Dermal Scaffold in Abdominal Wall Reconstruction. Am J Surg 199: 22-27.

6. Fischer JP, Wink JD, Nelson JA, Kovach SJ $3^{\text {rd }}$ (2014) Among 1,706 cases of abdominal wall reconstruction, what factors influence the occurrence of major operative complications?. Surgery 155: 311-319.

7. Sriussadaporn S, Sriussadaporn S, Pak-Art R, Kritayakirana K, Prichayudh $\mathrm{S}$, et al. (2013) Management of difficult abdominal wall problems by components separation methods: a preliminary study in Thailand. J Med Assoc Thai 96: 1449-1462.

8. Rosen MJ, Bauer JJ, Harmaty M, Carbonell AM, Cobb WS, et al. (2017) Multicenter, Prospective, Longitudinal Study of the Recurrence, Surgical Site Infection, and Quality of Life After Contaminated Ventral Hernia Repair Using Biosynthetic Absorbable Mesh: The COBRA Study. Ann Surg 265: 205-211.

9. Bernard C, Polliand C, Mutelica L, Champault G (2007) Repair of giant incisional abdominal wall hernias using open intraperitoneal mesh. Hernia 11: $315-320$.

10. Heartsill L, Richards ML, Arfai N, Lee A, Bingener-Casey J, et al. (2005) Open Rives-Stoppa ventral hernia repair made simple and successful but not for everyone. Hernia 9: 162-166.

11. Shih PK (2015) Difficult abdominal wall closure: component separation versus partition technique. Hernia 19: 301-305.

12. Raigani S, De Silva GS, Criss CN, Novitsky YW, Rosen MJ (2014) The impact of developing a comprehensive hernia center on the referral patterns and complexity of hernia care. Hernia 18: 625-630.

13. Rosen MJ, Krpata DM, Ermlich B, Blatnik JA (2013) A 5 year clinical experience with single staged repairs of infected and contaminated abdominal wall defects utilizing biological mesh. Ann Surg 257: 991-996.

14. Albright E, Diaz D, Davenport D, Roth JS (2011) The component separation technique for hernia repair: a comparison of open and endoscopic techniques. Am Surg 77: 839-843.

15. Roth JS, Brathwaite C, Hacker K, Fisher K, King J (2015) Complex ventral hernia repair with a human acellular dermal matrix. Hernia 19: 247-252.

16. Mommers EH, Wegdam JA, Nienhuijs SW, de Vries Reilingh TS (2016) How to perform the endoscopically assisted components separation technique (ECST) for large ventral hernia repair. Hernia 20: 441-447.

17. Ferrari GC, Miranda A, Di Lernia S, Sansonna F, Magistro C, et al. (2008) Laparoscopic repair of incisional hernia: outcomes of 100 consecutive cases comprising 25 wall defects larger than $15 \mathrm{~cm}$. Surg Endosc 22: 11731179 .

18. Wright BE, Niskanen BD, Peterson DJ, Ney AL, Odland MD, et al. (2002) Laparoscopic ventral hernia repair: are there comparative advantages over traditional methods of repair? Am Surg 68: 291-295.

19. Gonzalez R, Rehnke RD, Ramaswamy A, Smith CD, Clarke JM, et al. (2005) Components separation technique and laparoscopic approach: a review of two evolving strategies for ventral hernia repair. Am Surg 71: 598-605.

20. Singh DP, Zahiri HR, Gastman B, Holton LH $3^{\text {rd }}$, Stromberg JA, et al. (2014) A modified approach to component separation using biological graft as a load sharing onlay reinforcement for the repair of complex ventral hernia. Surgical Innovation 21: 137-146.

21. Pauli EM, Wang J, Petro CC, Juza RM, Novitsky YW, et al. (2015) Posterior component separation with transversus abdominis release successfully addresses recurrent ventral hernias following anterior component separation. Hernia 19: 285-291.

22. Jones CM, Winder JS, Potochny JD, Pauli EM (2016) Posterior component separation with transversus abdominis release: technique, utility and outcomes in complex abdominal wall reconstruction. Plast Reconstr Surg 137: 636-646. 